\title{
Metatarsophalangeal Joint 1
}

National Cancer Institute

\section{Source}

National Cancer Institute. Metatarsophalangeal Joint 1. NCI Thesaurus. Code C102321.

A condyloid synovial joint within the first digit of the foot connecting metatarsal with the proximal phalanx. 